\title{
Primary Thyroid Lymphoma: Two Case Reports and Review of Literature
}

Dr. Rinku Susan Kurian ${ }^{1 *}$, Dr. Sankar. $S^{2}$

${ }^{1}$ Junior resident, Dept. of pathology, Govt. Medical College, Kottayam
${ }^{2}$ Professor and Head of the Department, Dept. of Pathology, Govt. Medical College, Kottayam

$\begin{array}{cl}\text { Article History } & \begin{array}{l}\text { Abstract: Primary lymphoma of thyroid is a rare entity among thyroid diseases } \\ \text { Received: } 26.11 .2020\end{array} \\ \text { which constitute only 5\% of all thyroid malignancies. Primary thyroid lymphomas } \\ \text { Published: } 30.12 .2020\end{array} \quad \begin{aligned} & \text { are almost always associated with chronic lymphocytic thyroiditis. Most of them } \\ & \text { are B-cell origin Non-Hodgkin lymphomas, most common subtype is diffuse large } \\ & \text { B-cell lymphoma (DLBCL) followed by Mucosa associated lymphoid tissue } \\ & \text { (MALT) lymphoma. Treatment and outcome of primary thyroid lymphoma } \\ & \text { https://www.easpublisher.com } \\ & \text { depends on histological subtype and stage of the disease. Here we report two cases } \\ & \text { of primary thyroid lymphoma of B-cell origin diffuse large B-cell lymphoma and } \\ & \text { MALT lymphoma. First case is a 48 years old lady who presented with diffuse } \\ & \text { enlargement of thyroid with retrosternal extension complained of breathlessness } \\ & \text { and chest discomfort, which was confirmed by MRI scan. FNAC was Lymphocytic } \\ & \text { thyroiditis-Bethesda Category II. She underwent total thyroidectomy due to } \\ & \text { compression symptoms and histopathological diagnosis was diffuse large B cell } \\ & \text { lymphoma after immunohistochemistry. Second case is a 72 years old man who } \\ & \text { presented with a huge thyroid mass with rapid increase in size over one month } \\ & \text { duration, associated with hoarseness of voice and difficulty in swallowing. CT scan } \\ & \text { revealed grossly enlarged thyroid extending into prevertebral area causing } \\ & \text { compression of esophagus. Total thyroidectomy was done, final diagnosis of which } \\ & \text { was Non-Hodgkin lymphoma, possibly MALT lymphoma with associated diffuse } \\ & \text { high grade areas in a background of lymphocytic thyroiditis. } \\ & \text { Keywords: Primary thyroid lymphoma, diffuse large B-cell lymphoma, MALT } \\ & \text { lymphoma. }\end{aligned}$

Copyright ( 2020 The Author(s): This is an open-access article distributed under the terms of the Creative Commons Attribution 4.0 International License (CC BY-NC 4.0) which permits unrestricted use, distribution, and reproduction in any medium for non-commercial use provided the original author and source are credited.

\section{INTRODUCTION}

Primary thyroid lymphoma is a rare thyroid disease that constitutes about $5 \%$ of all thyroid malignancies and $2 \%$ of extranodal lymphomas. It affects thyroid gland and its regional lymphnodes only. It occurs predominantly in females (Female to male ratio of 3-4:1) and mean age of presention is $65 \mathrm{yrs}$. It is almost always associated with chronic lymphocytic (Hashimoto) thyroiditis. Most of the are B- cell origin and most common subtype is diffuse large B-cell lymphoma (DLBCL) followed by MALT lymphoma. Here we report two different cases of Primary thyroid lymphoma, DLBCL and MALT lymphoma associated with lymphocytic thyroiditis.

\section{Case Presentation} Case 1

A 48 years old lady presented with thyroid swelling which is gradually increasing in size for 10 years duration. Then she complained of breathlessness and chest discomfort for the past 2 months from admission. There was a family history of thyroid disease in siblings. No history of any B symptoms. On examination, patient was vitally stable and there was no generalized lymphadenopathy /hepatosplenomegaly. A large non-tender irregular nodular mass involving the whole thyroid with lower border not palpable felt on palpation of neck. Dull note was elicited on sternal percussion.

MRI scan of neck and upper thorax revealed further clarity regarding retrosternal extension. Thyroid was diffusely enlarged with multiple mixed signal intensity nodules of varying size, a few with T1w hyperintense signal within it, largest in Right lobe. At the time of admission, TFT was done, F.T3 -380, F.T41.5, and S.TSH-0.001. Hb- $13.4 \mathrm{~g} / \mathrm{dl}$, Total count-10,300 and Different count- N54\% L29\% Mixed16\%.

\section{FNAC diagnosis: Lymphocytic thyroiditis-Bethesda category II}

She underwent total thyroidectomy; we received a diffusely enlarged thyroid weighing $220 \mathrm{gm}$, 
cut section of right lobe showed an ill-defined grey white area measuring $3.5 \mathrm{~cm}$ in greatest dimension, adjacent tissue showing multiple colloid filled nodules of varying size (figure 1).

Microscopically thyroid tissue with extensive infiltration by medium and large sized cells having fine dispersed chromatin and small nucleoli with minimal amount of cytoplasm showing increased mitosis. No reactive lymphoid follicles/ plasma cells (figure 2). Seen Immunohistochemistry showed that the neoplastic cells are LCA and CD 20 positive.CK and CD3 negative (figure $3,4,5,6$ ).

Final diagnosis: Non-Hodgkin lymphoma thyroid high grade possibly diffuse large B cell lymphoma.

\section{CASE 1}

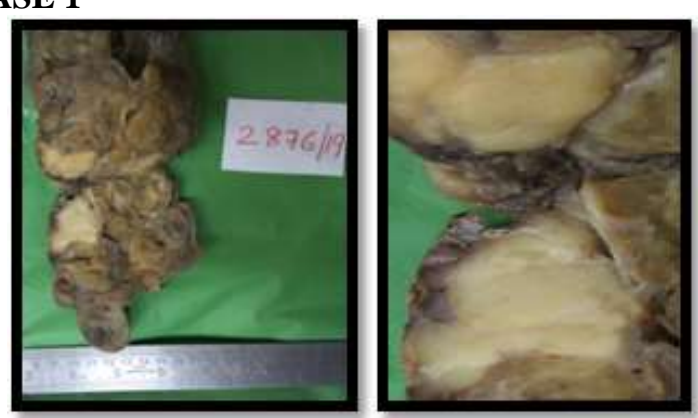

Fig-1: Gross of thyroid with grey white homogenous area

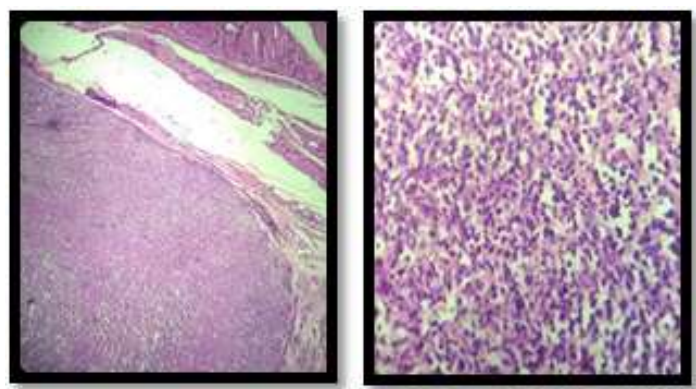

Fig-2: Microscopy- H\&E stain (scanner and 400X)

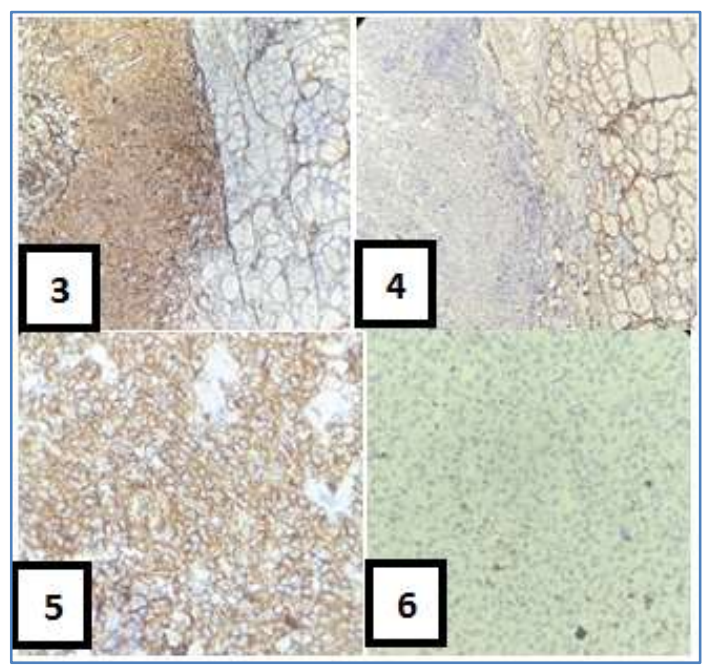

Fig-3, 4, 5 and 6 are immunohistochemistry of LCA (40X), CK (40X), CD20 (400X) and CD3 (400X) respectively
Case 2

A 72 years old man presented with a thyroid swelling which was rapidly increasing in size over 1 month and was associatied with hoarseness of voice and difficulty in swallowing. There was history of loss of appetite. He was vitally stable. On examination of neck, diffusely enlarged non-tender, firm thyroid mass was palpable without any cervical lymphadenopathy. No generalized lymphadenopathy and hepatosplenomegaly.

USG neck showed enlargement of both lobes with heteroechoic echotexture and multiple hypoechoic areas. CT base of skull to upper thorax revealed grossly enlarged thyroid that extends into prevertebral region compressing the esophagus. On admission, TFT was F.T3-27.13, F.T4-0.57and S.TSH-91.85. Hb-10.1g/dl, Total WBC count-5440cells/mm3 and Differential count-N60\%L42\%M1.7\% Eo 4.2\%Baso1.1\%.

FNAC diagnosis: Malignant cells present, suggestive of poorly differentiated carcinoma/LymphomaBethesda Category V

Total thyroidectomy was done; we received a grossly enlarged thyroid weighing $40 \mathrm{gm}$. Cut surface show patchy whitish homogenous areas in both lobes. No nodules seen.

Microscopy showed thyroid tissue diffusely infiltrated by cells with vesicular nuclei with distint nucleoli and amphophilic cytoplasm. Numerous lymphocytes forming aggregates with plasma cells seen scattered in stroma. Atypical cells seen invading the thyroid follicles forming lymphoepithelial lesions in some foci. There is fibrosis and hurthle cell change in follicles (figure7). Immunohistochemistry showed epithelial cells are CK positive with background LCA positive lymphocytes, majority of the lymphocytes are CD20 positive with a few scattered CD3 positive cells (figure 8, 9, 10, 11).

Final diagnosis: Non-Hodgkin Lymphoma thyroid- possibly MALT lymphoma with diffuse high grade areas in a background of lymphocytic thyroiditis.

\section{CASE 2}

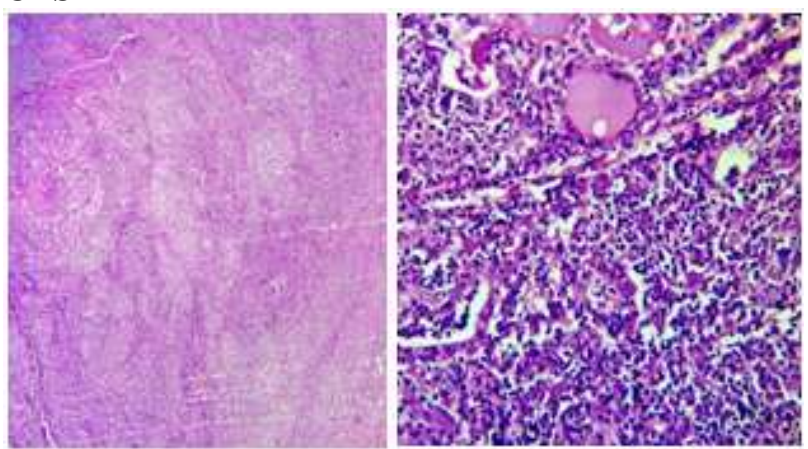

Fig-7: Microscopy -H\&E stain (scanner and 400X) 


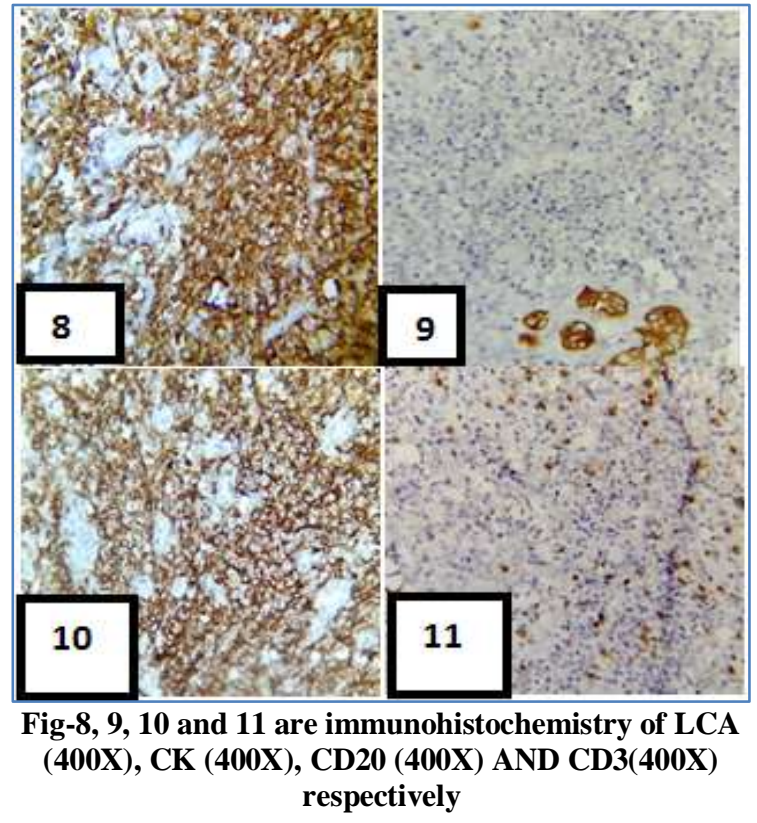

\section{DiscuSSION}

Thyroid lymphoma can be classified into primary and secondary. Primary thyroid lymphoma is confined to thyroid and its regional lymphnodes. Secondary originates from non-thyroid tissue that metastasizes to thyroid gland with high mortality rate than primary [1]. Primary thyroid lymphoma is a rare disease, accounting for $5 \%$ of all thyroid malignancies. Diffuse large Bcell lymphoma (50-80\%) being the most common type of PTC followed by MALT lymphoma $(20-30 \%)$ and follicular lymphoma $(12 \%)[1,2]$. Some DLBCL constitute large cell transformation of MALT lymphomas [2]. Primary thyroid lymphoma predominantly affect females (Female to male ratio is 3$4: 1$, with mean age affected is 65 years [2]. A background of chronic lymphocytic thyroiditis or Hashimoto thyroiditis are found in $>90 \%$ of reported cases. But transformation from thyroiditis to primary thyroid lymphoma occurs in about $0.5 \%$ of cases $[3,4]$. Thyroid lymphomas often exhibit common homologous germline $\mathrm{VH}$ genes used by antithyroid antibodies futher implicating derivation from chronic lymphocytic thyroiditis [2, 4].

Usual presentation is mass in thyroid with or without cervical lymphadenopathy, rapid enlargement of which causes compression symptoms [2]. The two cases included in this study also showed symptoms of compression for which total thyroidectomy was performed. Constitutional (B symptoms) are rare. Radiological imaging such as ultrasound scan, CT and MRI usually shows diffusely enlarged thyroid gland and extent of compression. Also helps in staging of the disease [1].

FNAC has important role in diagnosing thyroid swellings, but it has a limited effect in the case of primary thyroid lymphomas. In some cases it is difficult to differentiate between thyroid lymphoma, lymphocytic thyroiditis and Anaplastic Carcinoma thyroid [1]. In this study, the two cases showed clinical and radiological features of multinodular goiter and thyroiditis, in which FNAC of one case was interpreted as Bethesda Category II (Lymphocytic thyroiditis) and other as Bethesda category V(suspicious of Poorly differentiated Carcinoma/Lymphoma). When FNA is combined with flow cytometry, it can give a complete diagnosis in $82 \%$ of cases. But still tissue biopsy remains as the gold standard of histological diagnosis [5].

It is very crucial to diagnose primary thyroid lymphoma subtype by histology, due to prognostic significance and very importantly therapeutic interventions are largely depends on histological subtype as well as stage of the disease [5]. Staging can be made by proper clinico-radiological correlation. DLBCL is treated with radiation and chemotherapy. MALT lymphoma localized treated with radiation and disseminated one by combined radiotherapy and chemotherapy. Total thyroidectomy is performed in the setting of compression symptoms like airway compromise as in our two cases $[3,5]$.

\section{CONCLUSION}

Clinicians should include primary thyroid lymphoma as a differential diagnosis when they are dealing with a rapidly enlarged thyroid. FNAC has got only limited role in the diagnosis of primary thyroid lymphoma where histopathological diagnosis with the support of immunohistochemistry remain the gold standard. As the prognosis and therapeutic intervention of primary lymphoma of thyroid depends on subtype of lymphoma and stage of the disease, a multidisciplinary approach encompassing clinical, radiological and histological details for deriving at a final diagnosis need to be emphasized.

\section{REFERENCE}

1. Alyami, H., Alsofyani, T., Bshait, M. B., \& Al-Osail, E. M. (2018). Primary Diffuse B-Cell Thyroid Lymphoma: Case Report and Literature Review. Case reports in oncology, 11(2), 505-510.

2. Ricardo, V., Lloyd, Robert, O.Y. (2017). WHO Classification of Tumors of Endocrine organs; IARC, $4^{\text {th }}$ edition, Chapter-2,137-138.

3. Stein, S. A., \& Wartofsky, L. (2013). Primary thyroid lymphoma: a clinical review. The Journal of Clinical Endocrinology \& Metabolism, 98(8), 3131-3138.

4. Papadakis, G., Tertipi, A., Papazian, M., Moustakas, K., \& Pappas, A. (2015). Case report: Primary thyroid lymphoma presenting as a rapidly enlarging thyroid mass. Endocrinol Metab Int J, l(1), 00002.

5. Kinnari, M., Cynthia, L. (2015). Thyroid lymphoma: A case report and literature review; World Journal of Otorhinolaryngology, 28; 5(3):82-89. 